Gut, 1983, 24, 288-292

\title{
Relationship between trace elements, sugar consumption, and taste in Crohn's disease
}

\author{
W J PENNY. J F MAYBERRY, P J AGGETT, J O GILBERT, \\ R G NEWCOMBE, AND J RHODES \\ From the Departments of Gastroenterology, Dietetics and Medical Statistics, University Hospital of Wales, \\ and the Centre for the Study of Metabolism of Trace Elements, University of Aberdeen, Aberdeen
}

SUmmary Seventy patients with Crohn's disease, 50 with ulcerative colitis, and 58 control subjects were questioned about their sugar consumption, measurements were made of their taste acuity, and blood levels of various trace elements including zinc and selenium were estimated. Sugar consumption was significantly increased in Crohn's disease $(p<0 \cdot 01)$. There was only a minor reduction in taste acuity for acid taste in Crohn's disease. Plasma zinc and whole blood selenium were reduced in Crohn's disease. No relationship was found between sugar consumption, plasma zinc, and taste acuity in Crohn's disease.

Although patients with Crohn's disease have an increased consumption of sucrose, the relevance of this finding remains unexplained. ${ }^{1-6}$ Zinc deficiency, which is common in Crohn's disease, ${ }^{78}$ may depress taste acuity ${ }^{9} 10$ and so cause patients to eat more sugar. We have examined the possibility that a high sugar intake in Crohn's disease may be due to a change in taste acuity and have also measured the plasma concentrations of zinc and copper, whole blood selenium, and activity of the seleno-enzyme glutathione peroxidase, relating them to the nutritional status of our patients. Patients with ulcerative colitis and healthy controls were used for comparison.

\section{Methods}

The study involved 70 patients with Crohn's disease and 50 with ulcerative colitis attending an outpatient clinic. Fifty-eight control subjects included relatives and friends who accompanied the patients as well as members of hospital staff. All who took part completed a questionnaire about sugar consumption and noted the quantities of sugar added to beverages and cereals as well as items of sweet foods taken daily. ${ }^{+6}$ A simple index of disease activity was calculated for Crohn's disease which has been shown to correlate with the one used by the National Cooperative Crohn's Disease Study Group. ${ }^{11}$ Blood

Received for publication 12 July 1982 was also taken into heparinised tubes free from trace metal. The plasma zinc and copper were determined by atomic absorption spectroscopy ${ }^{12}$ (Instrumentation Laboratories IL251 and IL751 Spectrometers). The serum albumin and alkaline phosphatase levels were measured on a Technicon SMA plus autoanalyser. The whole blood selenium concentrations were measured by a fluorometric method ${ }^{13}$ and whole blood glutathione peroxidase activity was assessed by an NAD linked technique. ${ }^{14}$

Taste acuity was measured in a random sample of both groups of patients and controls. Two types of taste threshold were noted - the detection and recognition threshold using a 'forced choice technique'. ${ }^{9}$ A series of solutions of sodium chloride, sucrose, and hydrochloric acid were prepared in graded concentrations. Three drops of solutions were applied to the tongue in a random manner: one drop of one of the above solutions and two drops of water. Subjects chose the solution which was different and the concentration at which this could be achieved consistently was noted. This was called the 'detection threshold'. The lowest concentration of solute which the patient could consistently recognise as salty, sour, or sweet was called the 'recognition threshold'.

\section{STATISTICAL METHODS}

Differences between patient groups were assessed using the unpaired $t$ test. Associations between variables in each group were assessed by plotting scatter diagrams and calculating product-moment 
correlation coefficients. Analysis of covariance was used to adjust differences in certain variables for the difference existing in other variables which were thought to influence them. Taste, copper, alkaline phosphatase, and selenium measurements were subjected to a Log transformation before analysis, as this improved the normality and homogeneity of various aspects of the data.

\section{Results}

The age and sex ratio of subjects are shown in Table 1. Control subjects were younger (mean $37 \cdot 3 \pm 10 \cdot 9$ years SD) than those with colitis $(45 \cdot 5 \pm 12 \cdot 4)$ and Crohn's patients $(44 \pm 14)$. The patients with colitis and Crohn's disease had fulfilled the usual criteria accepted for diagnosis. In the colitis group 30\% had total involvement, $35 \%$ distal colitis, and 35\% proctitis. The average duration of disease was $7 \cdot 8 \pm 5 \cdot 1$ years and two patients had had surgery. In the Crohn's group 75\% had ileocaecal disease with additional large or small bowel involvement. Nine per cent had small bowel involvement only and $16 \%$ had disease limited to the colon. The average duration of their disease was $10 \cdot 5 \pm 6 \cdot 6$ years and $67 \%$ had had surgery.

Crohn's patients ate significantly more items of sweet food and added more sucrose to their diet compared with controls $(p<0.001$ and $p<0.01$ respectively) or the colitics $(p<0.01$ and $p<0.05$; Tables 2 and 3 ). There was no difference between colitics and controls. The plasma zinc (Fig. 1) and albumin were significantly lower in Crohn's disease and ulcerative colitis. In Crohn's patients the zinc level tended to be slightly lower in those on corticosteroids $(11.12 \pm 0.17 v s 11.31 \pm 0.22 \mu \mathrm{mol} / \mathrm{l})$ but the difference was not statistically significant. The whole blood selenium was also lower in Crohn's disease but not in the colitics. The glutathione peroxidase level was reduced in Crohn's disease $(3 \cdot 2 \pm 0 \cdot 14$ vs $3.52 \pm 0.12 \mathrm{U} / \mathrm{ml}$ ) but this did not reach statistical significance. The alkaline phosphatase was significantly raised in Crohn's patients but the slight increase observed in those with ulcerative colitis did not reach statistical significance.

Table 1 Age and sex control subjects and patients with ulcerative colitis and Crohn's disease (mean $\pm S D$ )

\begin{tabular}{llll}
\hline & $\begin{array}{l}\text { Controls } \\
(n=58)\end{array}$ & $\begin{array}{l}\text { Ulcerative } \\
\text { colitis } \\
(n=50)\end{array}$ & $\begin{array}{l}\text { Crohn's } \\
\text { disease } \\
(n=70)\end{array}$ \\
\hline Age $(\mathrm{yr})$ & $37 \cdot 3 \pm 10 \cdot 9$ & $45 \cdot 5 \pm 12 \cdot 4$ & $44 \pm 14$ \\
Men/women ratio & $0 \cdot 7$ & $0 \cdot 61$ & 0.75 \\
\hline
\end{tabular}

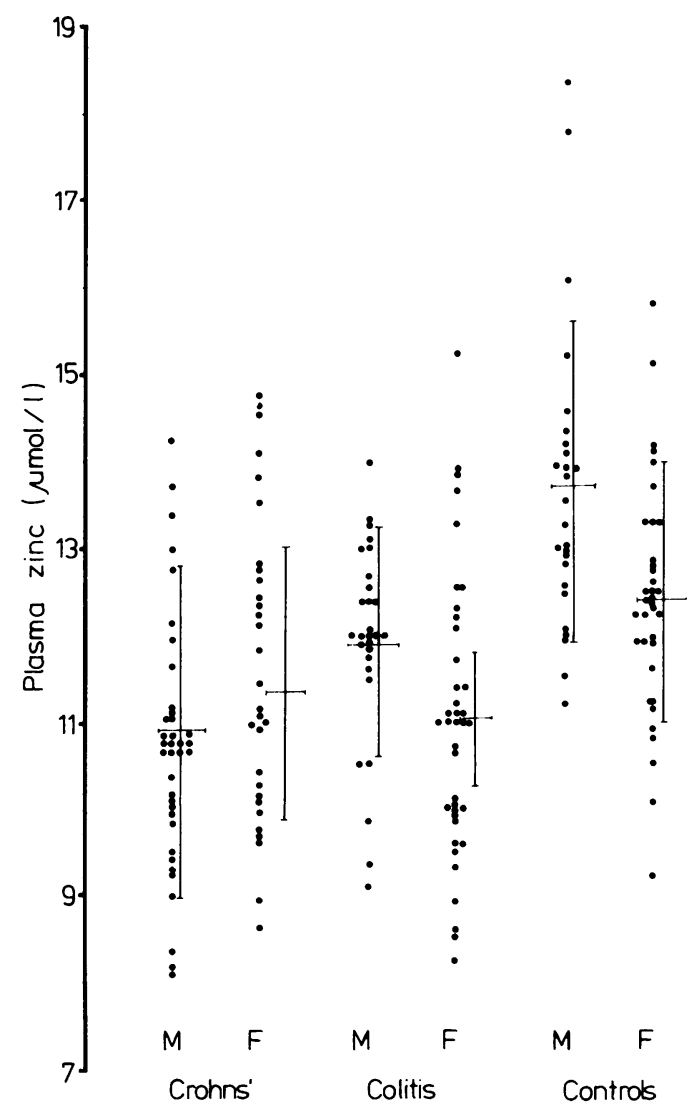

Fig. 1 Plasma zinc levels in Crohn's disease, patients with ulcerative colitis, and controls. Mean and standard deviations are given for men and women in each group. Unpaired t test comparing patients with Crohn's disease and controls, for men $p<0.01$, for women $p<0.05$; comparing colitis and controls, for men and women $p<0 \cdot 05$. Groups with colitis and Crohn's disease did not differ significantly from each other.

A statistically significant correlation $(\mathrm{p}<0.001)$ was found between plasma zinc and albumin. On adjustment for the albumin level the deficiency of plasma zinc remained significant in the Crohn's group $(p<0.01)$ but not in the colitics. The difference in whole blood selenium concentrations was eliminated by correction for plasma albumin by analysis of covariance.

In Crohn's patients there was a significant correlation between the cxtent of disease and serum albumin $(\mathrm{p}<0.05)$ and alkaline phosphatase levels $(p<0.05)$ and also between disease activity and serum albumin $(\mathrm{p}<0 \cdot 05)$.

Taste sensitivity was measured in a random 
Table 2 Grams of sucrose added to be'verages and cereals, number of sween foods' from standard list eaten daily, and biochemical me'asureme'nts for thre'e groups of subjects (me'an $\pm S E$ )

\begin{tabular}{|c|c|c|c|}
\hline & $\begin{array}{l}\text { (ontrols } \\
(n=58)\end{array}$ & $\begin{array}{l}\text { Ulcerative colitis } \\
(n=50)\end{array}$ & $\begin{array}{l}\text { Crohn's discease } \\
(n=7())\end{array}$ \\
\hline Added sucrose daily $(g)$ & $29 \cdot 2 \pm 6 \cdot 3$ & $34 \cdot(1 \pm 7 \cdot 3$ & $6.5 \cdot 1 \pm 9 \cdot 5$ \\
\hline 'Swects' daily (no.) & $2 \cdot 15 \pm 0.18$ & $2 \cdot 6 \pm 0 \cdot 22$ & $3 \cdot 37 \pm 0 \cdot 18$ \\
\hline Scrum alkaline phosphatasc (IU//) & $78 \cdot 44 \pm 3 \cdot 2$ & $91 \cdot 12 \pm 6 \cdot 8$ & $117 \cdot(17 \pm 6 \cdot 5$ \\
\hline Serum albumin $(\mathrm{g} / \mathrm{l})$ & $46 \cdot 8 \pm(1) \cdot 36$ & $45 \cdot(14 \pm 0.58$ & $42 \cdot 68 \pm(0 \cdot 59$ \\
\hline Plasma zinc $(\mu \mathrm{mol} / 1)$ & $1.3 \cdot() 1 \pm(0 \cdot 23$ & $11 \cdot 42 \pm(1.25$ & $11 \cdot 23 \pm(1 \cdot 21$ \\
\hline Plasmil copper $(\mu \mathrm{mol} / \mathrm{l})$ & $16 \cdot 4 \pm 0 \cdot 60$ & $17 \cdot 68 \pm(1 \cdot 53$ & $17 \cdot 76 \pm 0 \cdot 50$ \\
\hline Whole blood sclenium $(\mu \mathrm{mol} / \mathrm{l})$ & $1 \cdot 8.5 \pm() \cdot 50$ & $1 \cdot 77 \pm 4 \cdot 7$ & $1 \cdot 7.3 \pm() \cdot 60$ \\
\hline Whole blood glutathionc peroxidase (U/ml) & $3 \cdot 52 \pm(1 \cdot 12$ & $3.79 \pm 0.19$ & $3 \cdot 2 \pm(1 \cdot 14$ \\
\hline
\end{tabular}

sample of 14 controls, 17 with ulcerative colitis and 23 with Crohn's disease. Both the 'detection threshold' and the 'recognition threshold' for acid taste was higher in Crohn's disease compared with those with ulcerative colitis or the controls $(p<0) \cdot(05$; Fig. 2) but there was no difference for other taste modalities between the groups and patients with ulcerative colitis showed no difference from controls. The differences in acid taste sensitivity between Crohn's patients and controls disappear, however, on adjustment for either zinc or albumin levels in an analysis of covariance. Similarly, there was no correlation between sugar consumption and zinc levels $(r=0.03, p=0.8)$ or between sugar consumption and taste sensitivity.

\section{Discussion}

Our patients with Crohn's disease again show increased consumption of sugar and sweet foods compared with patients who have colitis and healthy controls. Our Crohn's group also had a reduced plasma zinc and albumin with a rise of alkaline phosphatase levels compared with controls. The low level of whole blood selenium in Crohn's disease probably reflects their impaired nutritional status. The erythrocyte glutathione peroxidase, a seleno- enzyme which has been shown to reflect selenium status in animals and man. ${ }^{15} 16$ was also reduced in Crohn's patients but this was not statistically significant. Selenium deficiency has been rarely associated with clinical disease in man, although deficiency causes various problems in other mammals. ${ }^{17}$ In man, deficiency has been reported after total parenteral nutrition ${ }^{18}$ and in patients with severe malnutrition and inflammatory bowel disease. ${ }^{19} 20$

There is no single simple measurement of zinc status which is entirely satisfactory, although most studies have used the plasma level as a guide. ${ }^{8} 21$ Alternatives are to measure the hair zinc ${ }^{22}$ or the leucocyte zinc content. ${ }^{2324}$ Acute infection and stress may transiently depress the plasma zinc ${ }^{25}$ through leucocyte endogenous mediator substances. This mechanism is unlikely in our outpatient population with quiescent Crohn's disease. Previous work has shown that zinc absorption is impaired in Crohn's disease ${ }^{826}$ and plasma levels tend to be low even in the presence of a normal intake. We have found a reduced plasma zinc in conjunction with reduced serum albumin but the low plasma zinc stands as an independent variable which is related to both the disease activity and extent of disease. Previous measurements of plasma zinc have also

Table 3 Significance of differences between different groups for dietary intake of sucrose and 'sweet foods' and biochemical measurements shown in Table 2

\begin{tabular}{llll}
\hline & Control vs Crohn's & Control vs colitics & Crohn's vs colitics \\
\hline Added sucrose daily $(\mathrm{g})$ & $\mathrm{p}<0.01$ & $\mathrm{NS}$ & $\mathrm{p}<0 \cdot 01$ \\
'Sweets' daily $(\mathrm{no})$. & $\mathrm{p}<0.001$ & $\mathrm{NS}$ & $\mathrm{p}<0.05$ \\
Serum alkaline phosphatase $(\mathrm{IU} / \mathrm{l})$ & $\mathrm{p}<0.001$ & $0.05<\mathrm{p}<0 \cdot 1$ & $\mathrm{p}<0.01$ \\
Serum albumin $(\mathrm{g} / \mathrm{l})$ & $\mathrm{p}<0.001$ & $\mathrm{p}<0 \cdot 05$ & $\mathrm{p}<0.01$ \\
Plasma zinc $(\mu \mathrm{mol} / \mathrm{l})$ & $\mathrm{p}<0.001$ & $\mathrm{p}<0 \cdot 001$ & $\mathrm{NS}$ \\
Plasma copper $(\mu \mathrm{mol} / \mathrm{l})$ & $\mathrm{NS}$ & $\mathrm{NS}$ & $\mathrm{NS}$ \\
Whole blood selenium $(\mu \mathrm{mol} / \mathrm{l})$ & $\mathrm{p}<0.05$ & $\mathrm{NS}$ & $\mathrm{N}<0.05$ \\
Whole blood glutathione peroxidase $(\mathrm{U} / \mathrm{ml})$ & $\mathrm{NS}$ & $\mathrm{NS}$ & \\
\hline
\end{tabular}




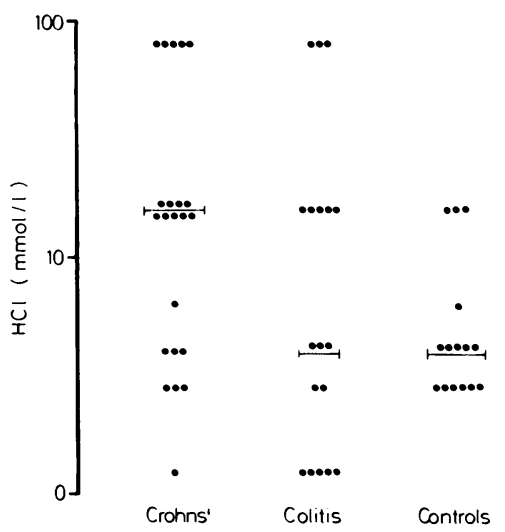

Fig. 2 Thresholds to sour taste with different concentrations of hydrochloric acid in patients with Crohn's disease, ulcerative colitis, and controls. The median 'detection threshold' is given for each group. The concentration of $\mathrm{HCl}$ is given on a logarithmic scale. Comparison of patients with Crohn's disease with both controls and patients with colitis using an unpaired Student's t test $p<0.05$.

shown a close relationship to disease activity. ${ }^{7}$ The relevance of a reduced plasma zinc concentration in patients with Crohn's disease who are apparently well is not clear. It is known, however, that a normal zinc status is important for cellular immunity ${ }^{27-29}$ and wound healing, ${ }^{301} 31$ both of which are often impaired in Crohn's disease..$^{32} 33$

Taste was measured on a random sample of one-third of the subjects. There was little difference between groups apart from some impairment of acuity for $\mathrm{HCl}$ in Crohn's disease. In the acute phase of their disease our findings may have been different and subsequent improvement may be associated with improved taste acuity. Similarly, we have failed to show any relationship between increased sugar consumption, low plasma zinc, and impaired acuity for sweet taste.

One study ${ }^{7}$ on hospitalised patients with an acute exacerbation of Crohn's disease showed a decreased serum zinc concentration which was associated with a disturbance of taste acuity, while another study ${ }^{8}$ in a small group of 14 patients showed an impairment of sweet taste only in those patients with low zinc concentration.

An increased consumption of sugar in Crohn's disease was first noted in West Germany ${ }^{12}$ and subsequent studies in Cardiff, Birmingham, Bristol, and Tel Aviv have all confirmed this difference. ${ }^{3-6}$ It has been assessed by some observers using an interview technique, with a dietitian, while others have resorted to weighing all items of food over several days but this latter method introduces its own problems." We have simply asked about the quantity of sugar added to beverages and cereals and the consumption of certain sweet foods which are commonly eaten, since this technique has been shown to be reliable. ${ }^{46}$ The increased sugar consumption remains unexplained but may be part of an attempt to increase calorie intake.

It is difficult to measure taste accurately and we have followed the procedure worked out by Henkin" to overcome the major problems inherent in this measurement. Our findings are similar to those of Casper and Sommer ${ }^{34}$ who were unable to show impaired taste acuity in patients with Crohn's disease and it seems unlikely that any minor differences in taste acuity identified in patients with Crohn's disease would account for the major differences in sugar consumption which have been consistently demonstrated.

We wish to thank Dr D Stansby for measuring the serum albumin and alkaline phosphatase levels.

\section{References}

1 Martini GA, Brandes JW. Increased consumption of refined carbohydrates in patients with Crohn's disease. Klin Wochenschr 1976; 54: 367-71.

2 Miller B, Fervers F, Rohbeck R. Strohmever G. Zuckerhonsum bein patienten mit morbus Crohn. Vehr Dtsch Ges Inn Med 1976; 82: 922-4.

3 Thornton JR, Emmett PM, Heaton KW. Diet and Crohn's disease: characteristics of the pre-illness diet. Br Med J 1979: 2: 762-4.

4 Mayberry JF. Rhodes J. Newcombe RG. Increased sugar consumption in Crohn's disease. Digestion 1980: 20: $323-6$.

5 Silkoff K. Hallak A, Yegena L, Rozen P. Mayberry JF. Rhodes J, Newcombe RG. Consumption of refined carbohydrate by patients with Crohn's disease in Tel-Aviv-Yafo. Postgrad Med J 1980; 56: 28-32.

6 Mayberry JF. Rhodes J. Allan R. Newcombe RG. Regan G, Chamberlain LM, Wragg KG. Diet in Crohn's disease: two studies of current and previous habits in newly diagnosed patients. Dig Dis 1981: 26: 444-8.

7 Solomons NW, Rosenberg TH, Sandstead HH. VoKhacta KP. Zinc deficiency in Crohn's disease. Digestion 1977; 16: 87.

8 McClain C, Soutor C, Zieve L. Zinc deficiency, a complication of Crohn's disease. Gastroenterology 1980; 78: 272-9.

9 Henkin RI, Graziadei PPG. Bradley DF. The molecular basis of taste and its disorders. Ann Intern Med 1969; 71: 791-821.

10 Catalanotto FA. The trace metal zinc and taste. Am J 
Clin Nutr 1978: 31: 1098-103.

11 Harvey RF. Bradshaw JM. A simple index of Crohn's disease activitv. Lancet 1980): 1: 514 .

12 Meret S. Henkin RI. Simultaneous direct estimation by atomic absorption spectrophotometry of copper and zinc in serum, urine and cerebrospinal fluid. Clin Chem 1971: 17: 369-73.

13 Olsen JS. Modification of the official fluorometric method for selenium in plants. $J$ Assoc Off Anal Chem 1975: 58: 117-21.

14 Paglia DE. Valentine WN. Studies on the quantitative and qualitative characterisation of erythrocyte glutathione peroxidase. J Lab Clin Med 1967: 70: $158-69$.

15 McMurray $\mathrm{CH}$. Blanchflower WJ. The levels of selenium and glutathione peroxidase activity in blood of sheep. cows and pigs. Res Vet Sci 1976: 20: 229-31.

16 Perona G. Cellerino R. Guidi GC. Moschini G. Stievano BM. Tregnaghi C. Erythrocytic glutathione peroxidase; its relationship to plasma selenium in man. Scand J Haematol 1977; 19: 116-20.

17 Schwarz K. Essentiality and metabolic functions of selenium. Med Clin N Am 1976; 60: 745-59.

18 Van Rij AM. Thomson CD. McKenzie JM. Robinson MF. Selenium deficiency in total parenteral nutrition. Am J Clin Nutr 1979: 32: 2076-85.

19 Fell GS, Shenkin A. Main A, Russell R. Human selenium deficiency. Proc Nutr Soc 1980; 39: 36A.

20) Spooner RJ, Campbell RA, Rumley AG, Stromberg P. Glutathione peroxidase in human selenium deficiency. Proc Nutr Soc 1980; 39: 37A.

21 Solomons NW. On the assessment of zinc and copper nutriture in man. Am J Clin Nutr 1979; 32: 856-71.

22 Hambidge KM, Hambidge C. Jacob M, Baum JD. Low levels of zinc in hair, anorexia, poor growth and hypogeusia in children. Pediatr Res 1972; 6: 868-74.
23 Jones RB. Keeling PWN. Hilton PJ. Thompson RPH. The relationship between leucocyte and muscle zinc in health and disease. Clin Sci 1981: 60: 237-9.

24 Aggett PJ. Harries JT. Current status of zinc in health and disease states. Arch Dis Childh 1979: 54: 909-17.

25 Solomons NW. Elson CO. Pekerek RS. Jacob R. Sandstead HH, Rosenberg IH. Leucocyte endogenous mediator (LEM) in Crohn's disease. Infect Immunol 1978: 22: 6.37-9.

26 Sturniolo CG. Molokhia MM. Shields R. Turnberg LA. Zinc absorption in Crohn's disease. (Gut 1980): 21: $387-91$.

27 Miller ER. Luecke RW. Ullrey DE. Biochemical. skeletal and allometric changes due to zinc deficiency in the baby pig. $J$ Nutr 1968 ; 95: 278-86.

28 Fraker PJ. Haas SM. Luecke RW. Effect of zinc deficiency on the immune response of the young adult A/J mouse. J Nutr 1977: 107: 1889-95.

29 Golden MHN. Golden BE. Narland PSEG. Jackson FA. Zinc and immunocompetence in protein-energy malnutrition. Lancet 1978: 1: 1226-8.

30 Sandstead HR, Lannier VC Jr. Shephard GH. Zinc and wound healing. Am J Clin Nutr 1974: 23: 51+9.

31 Biochemistry of zinc - role in wound healing. In: Hambidge KM, Nichols BL. Holliswood NY, eds. Zinc and copper in clinical medicine. Spectrum Publications, 1978: 15-24.

32 Sachar DB. Taub RN. Brown SM. Impaired lymphocyte responsiveness in inflammatory bowel disease. Gastroenterology 1973; 64: 203-9.

33 Meyers S. Sachar DB. Taub RN. Allergy to dinitrochlorobenzene and depression of $\mathrm{T}$ lymphocytes in Crohn's disease and ulcerative colitis. Gut 1976; 17: 911-5.

34 Kasper H. Sommer H. Taste thresholds in patients with Crohn's disease. J Hum Nutr 1980: 34: 455-6. 